\title{
Establishing a Northern Eurasian paleoecological database: The pollen data
}

\author{
University of Southampton, UK, 14-19 April 2008
}

Heather Binney ${ }^{1}$, M. Edwards ${ }^{1}$ and K. Willis ${ }^{2}$

'University of Southampton, UK; h.a.binney@soton.ac.uk; '2University of Oxford, UK

As part of the UK's QUEST program (http:// quest.bris.ac.uk/), QUEST Deglaciation (Q-

D) aims to evaluate the performance of a new, fast Earth System model in simulating the major changes of the late Quaternary (21 - 0 kyr). This model will include continuous simulations of vegetation patterns for this period, which can be evaluated by comparison with the reconstructed vegetation based upon pollen and macrofossil evidence. Additionally, Q-D focuses on the northern extra-tropics (NET), a region sensitive to climate change and thus particularly useful in evaluating the performance of climate models.

Previous data-model comparisons using the time-slice approach $(0,6,21 \mathrm{kyr}$ BP) (Bigelow et al. 2003; Kaplan et al. 2003) demonstrated the existence of a potentially large dataset of pollen sites in Northern Eurasia. However, continuous pollen records and related radiocarbon dates have not been brought together in a single database, and thus remained to be collected in full. The Global and European Pollen Databases (GPD \& EPD) indicate that these databases are a good source of material for North America and Europe but that a considerable proportion of sites in the Former Soviet Union (FSU) are not archived.

Furthermore, during the macrofossil workshop held in 2007 that was partly funded by PAGES (see PAGES News, 15(1): 27-28), it became apparent that the participants either had collected or knew of additional pollen data from these data-sparse regions. Therefore, it was decided to hold a second data-gathering workshop, this time to obtain well-dated pollen records from sites in the FSU during the critical climate interval $21 \mathrm{kyr}$ to present. The macrofossil and pollen data will be housed in the same database, providing the possibility to analyze the two datasets simultaneously. Crucial to such a database is the dating and the age-models, which are discussed further below.

The workshop took place at the University of Southampton, UK, and included nine academics who work entirely or primarily in the FSU.

\section{Outcomes of the workshop}

Pollen data from 87 sites were added to the database during the four-day workshop

(Fig. 1). All sites are well dated and a small

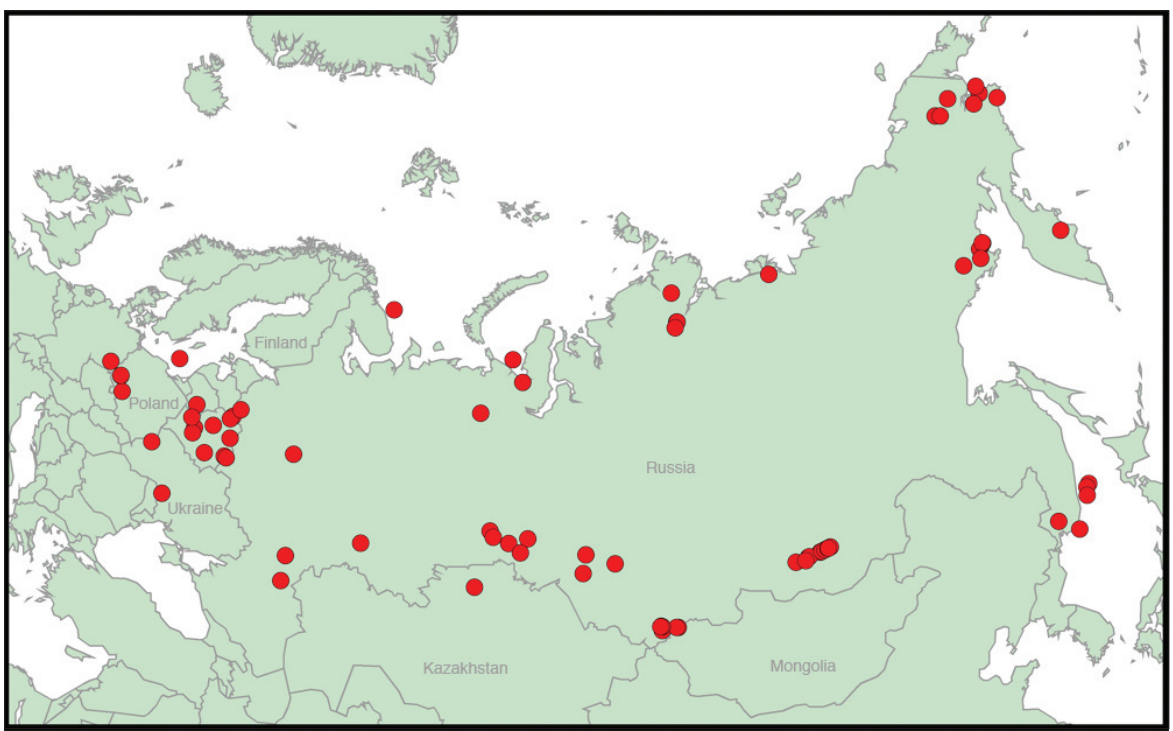

Figure 1: Location of the 87 sites with pollen data added during the workshop.

number of the sites extend as far back as $48 \mathrm{kyr}$ BP. These earlier sites were included because they were deemed useful for other projects, such as Quaternary QUEST (http:// quest.bris.ac.uk/research/themes/Quaternary.html). Metadata such as basin and lake size, sample type and landscape descriptions were included because these are important for understanding pollen source area and vegetation reconstructions. Taxonomy is also important, especially since the palynologists from the FSU often use a high level of taxonomic resolution in their investigations. All original identifications will be stored in the database alongside a standardized taxonomic list that will allow comparison with other regions in the NET. The pollen data will be stored as original counts with a facility for calculating percentages depending on the pollen sum required.

To allow data-model comparisons with optimal precision, all radiocarbon dates were calibrated to calendar years using the INTCAL04 calibration dataset (Reimer et al., 2004). Age-depth models were then constructed for each site for which a series of radiocarbon dates was available. This was undertaken by lan Matthews (Royal Holloway, University of London, UK) using Bayesian-based OXCAL4.0 sequence algorithms (http://c14.arch.ox.ac.uk/ see Bronk Ramsey, 2008). This approach is statistically rigorous and generates the best-constrained age models that can be determined using currently available calibration information. During the workshop, 35 individual agedepth models were constructed and the results for the remaining sites will be completed shortly.

\section{Use of the database}

Following data checking, the pollen data will be placed in the Eurasian Pollen Database, which will eventually be combined with the Eurasian Macrofossil Database (both Microsoft Access). The first objective will be to produce a synthesis of vegetation dynamics in Eurasia for the interval 21 kyr to present, of a temporal and spatial resolution suitable for comparison with the QUEST-Deglaciation GCMs. The combined Eurasian Pollen-Macrofossil database will also enable a better understanding of the position of key ecotones, such as the northern treeline, and the distribution of palynologically poorly represented species, such as Larix.

\section{Note}

The pollen element of the database will be available in 2009 via a public portal, following the production of a synthesis paper by workshop participants. If you wish to be kept informed of the progress of the database, please contact Heather Binney or visit http://gg-svr7.geog.soton.ac.uk/staff/mee/nepd/default.aspx

\section{References}

Bigelow, N.H. et al., 2003: Climate change and Arctic ecosystems I. Vegetation changes north of $55^{\circ} \mathrm{N}$ between the last glacial maximum, mid-Holocene and present, Journal of Geophysical Research, 108(D19): 8170

Bronk Ramsey, C. 2008: Deposition models for chronological records, Quaternary Science Reviews, 27: 42-60.

Kaplan, J.0. et al., 2003: Climate change and arctic ecosystems II: Modeling, paleodata-model comparisons, and future projections, Journal of Geophysical Research, 108(D19): 8171.

Reimer, P.J. et al., 2004: IntCal04 terrestrial radiocarbon age calibration, 0-26 cal kyr BP, Radiocarbon, 46(3): 1029-1058. 